\title{
O sentido da memória de homens e mulheres idosas: relação de gênero e sexualidade
}

\author{
The sense of memory of elderly men and women: gender relationship and sexuality \\ El sentido de la memoria de hombres y mujeres mayores: relación de género y sexualidade
}

Recebido: 04/02/2022 | Revisado: 12/02/2022 |Aceito: 17/02/2022 | Publicado: 26/02/2022

Rebecca Calheira Barreto

ORCID: https://orcid.org/0000-0001-7555-6714 Universidade Estadual do Sudoeste da Bahia, Brasil E-mail: rebeccacalheira@gmail.com

Vaniele Pereira Sampaio

ORCID: https://orcid.org/0000-0002-6301-1116 Universidade Estadual do Sudoeste da Bahia, Brasil E-mail: vanni.sampaio@hotmail.com

Thiago Angelo dos Santos Silva

ORCID: https://orcid.org/0000-0003-2049-5322 Universidade Estadual do Sudoeste da Bahia, Brasil E-mail: thiagoangelo16@hotmail.com

Anadir de Almeida Farias

ORCID: https://orcid.org/0000-0002-2124-531X Universidade Estadual do Sudoeste da Bahia, Brasil E-mail: nnhfarias@gmail.com

Maicla Oliveira da Silva

ORCID: https://orcid.org/0000-0002-4536-2262 Universidade Estadual do Sudoeste da Bahia, Brasil E-mail: maicla64@gmail.com Marcela Rossi Ribeiro

ORCID: https://orcid.org/0000-0002-7874-6086 Universidade Estadual do Sudoeste da Bahia, Brasil E-mail: marcelarossiribeiro@gmail.com

Luciana Araújo dos Reis

ORCID: https://orcid.org/0000-0002-0867-8057 Universidade Federal da Bahia, Brasil

E-mail: lucianauesb@yahoo.com.br

Vanda Palmarella Rodrigues

ORCID: https://orcid.org/0000-0002-5689-5910

Universidade Estadual do Sudoeste da Bahia, Brasil

E-mail: vprodrigues@uesb.edu.br

Edméia Campos Meira

ORCID: https://orcid.org/0000-0002-8328-6918

Universidade Estadual do Sudoeste da Bahia, Brasil

E-mail: edmeiameira@yahoo.com.br

Larisse Ramos de Oliveira

ORCID: https://orcid.org/0000-0003-4637-0747

Universidade Estadual do Sudoeste da Bahia, Brasil

E-mail: laryoliveira00@gmail.com

\begin{abstract}
Resumo
O estudo tem por objetivo compreender o sentido da memória de homens e mulheres idosas em vivência com a sexualidade, em construção sociocultural das diferenças de gênero. Tratou-se de uma pesquisa qualitativa, descritiva de caráter exploratório, com destaque para História Oral de Vida. Participaram da pesquisa nove pessoas idosas destes, quatro eram homens e cinco mulheres. Para a coleta de dados, foi utilizada a técnica de entrevistas abertas com roteiro semiestruturado, realizada no período de outubro a novembro de 2019 e de fevereiro a março de 2020 em uma cidade no interior da Bahia. A partir da análise dos dados por meio da Técnica de Análise de Conteúdo Temática emergiram três categorias: 1- Memórias do homem e da mulher idosa: infância e adolescência; 2- Memórias do homem e da mulher idosa: fase adulta; 3- Memórias do homem e da mulher idosa: velhice. Notou-se que o homem e a mulher idosa experimentaram e vivenciaram de forma distinta sua sexualidade em diversos momentos da sua história de vida e essa relação heterogênea entre o homem e a mulher idosa, advém de inúmeros aspectos que envolvem sentimentos, atitudes, comportamentos e desafios no seu processo de envelhecimento.
\end{abstract}

Palavras-chave: Envelhecimento; Sexualidade; Identidade de gênero. 


\begin{abstract}
The study aims to understand the meaning of memory of elderly men and women experiencing sexuality, in the sociocultural construction of gender differences. It was a qualitative, descriptive, exploratory research, with emphasis on Oral History of Life. Nine elderly people of these participated in the research, four were men and five women. For data collection, the technique of open interviews with a semi-structured script was used, carried out from October to November 2019 and from February to March 2020 in a city in the interior of Bahia. From the data analysis through the Thematic Content Analysis Technique, 3 categories emerged: 1- Memories of the elderly man and woman: childhood and adolescence; 2- Memories of the elderly man and woman: adulthood; 3- Memories of the elderly man and woman: old age. It was noted that elderly men and women experienced and experienced their sexuality in different ways at different times in their life history and this heterogeneous relationship between elderly men and women comes from numerous aspects involving feelings, attitudes, behaviors and challenges in your aging process.
\end{abstract}

Keywords: Aging; Sexuality; Gender identity.

\title{
Resumen
}

El estudio tiene como objetivo comprender el significado de la memoria de hombres y mujeres mayores experimentando la sexualidad, en la construcción sociocultural de las diferencias de género. Fue una investigación cualitativa, descriptiva, exploratoria, con énfasis en la Historia Oral de la Vida. Nueve ancianos de estos participaron en la investigación, cuatro eran hombres y cinco mujeres. Para la recolección de datos se utilizó la técnica de entrevistas abiertas con guión semiestructurado, realizadas de octubre a noviembre de 2019 y de febrero a marzo de 2020 en una ciudad del interior de Bahía. Del análisis de datos a través de la Técnica de Análisis de Contenido Temático, surgieron 3 categorías: 1- Memorias del anciano y de la anciana: infancia y adolescencia; 2- Recuerdos del anciano y de la anciana: edad adulta; 3- Recuerdos del anciano y de la anciana: vejez. Se observó que hombres y mujeres mayores vivieron y vivieron su sexualidad de diferentes formas en diferentes momentos de su historia de vida y esta relación heterogénea entre hombres y mujeres mayores surge de numerosos aspectos que involucran sentimientos, actitudes, comportamientos y desafíos en su proceso de envejecimiento.

Palabras clave: Envejecimiento; Sexualidad; Identidad de género.

\section{Introdução}

O envelhecimento humano é definido como a última fase do ciclo vital, no qual é marcado por eventos de natureza múltipla como mudanças tanto biológica como física, emocional, social, cultural, espiritual e também na ausência no meio social com privações em determinados papéis. Em seu sentido de origem, a velhice refere-se à idade avançada, ao estado ou condição de ser velho não associado ao processo de saúde-doença mais sim, inerente ao processo natural a vivenciar um envelhecimento ativo e saudável com autonomia, mesmo que exista limitações nesse processo de senescência (Paula et al., 2021).

Nessa perspectiva de envelhecimento, a proporção de pessoas com idade igual ou superior a 60 anos está crescendo em maior quantidade em relação aos outros grupos etários. À vista disso, a previsão de aumento até 2050 é de dois bilhões, sendo as pessoas idosas $12 \%$ da população mundial, com estimativa de chegar a $22 \%$ neste mesmo ano (Nascimento et al., 2020; Scult et al, 2015).

No tocante à sexualidade na velhice hoje, ainda pode ser considerado como um estigma, pois, envelhecer, muitas vezes, se relaciona com distanciamento social, assexualidade e o desgaste físico e mental, desconsiderando os desejos dos idosos durante o processo de envelhecimento. Logo, compreender a sexualidade da pessoa idosa considerando seu sentido integral, parte do pressuposto de que ela não é somente um fator biológico que se funde apenas no ato sexual em si, mas a um fator condicionado pela cultura, pelos valores morais e ambiente social o que envolve tanto os aspectos psicológicos quanto emocionais (Fernandes-Eloi et al, 2017; Gama, 2021; Oliveira et al, 2021).

A sexualidade faz parte da existência humana, na velhice ela é um seguimento de um processo que se iniciou na infância, que envolve sentimentos de alegria, culpa, vergonha e repressão de cada um, atrelada às modificações fisiológicas e anatômicas advindas com o tempo e idade, as quais determinam o comportamento sexual nessa etapa da vida. Além disso, a falta de conhecimento e a incompreensão decorrente da pressão exercida socialmente e do conceito estigmatizador confirmam esses sentimentos demonstrados pela pessoa idosa em algum momento de suas vidas (Gama, 2021; Vieira et al., 2016). 
Muitos idosos ainda apresentam sentir o desejo sexual, além da relação e a troca de carinho e carícias sem coito, uma vez que, se percebem na vontade de procurar e obter prazer, porém, o preconceito pela temática limita a sexualidade dos idosos nessa fase da vida, a qual contribui para sua baixa autoestima, prejudicando assim a sua qualidade de vida. Dessa forma, não aceitar a sexualidade nesse processo do envelhecimento é resultado da falta de discussões e da ausência de informação correta acerca do tema (Gama, 2021; Vieira, Coutinho et al., 2016).

Ademais, diversos são os fatores que contribuem para formar definições da sexualidade nas diferentes organizações, a exemplo das distintas formas como os grupos sociais, religião, as condições de vida, os modelos de relações entre os sexos, o uso do corpo e, as experiências vivenciadas ao decorrer da vida. Nota-se também que a sexualidade, como produto de um seguimento histórico, sofre influências de várias organizações, como a família, a sociedade e a igreja, sendo vista como algo impuro, consequentemente potencializando a discriminação e um estereótipo preconceituoso, dado que, culturalmente, a velhice está atrelada à pureza, à perda do erotismo, a impotência e à assexualidade (Souza et al, 2019).

Convém notar que, o sentido da sexualidade traz consigo as marcas das relações de gênero e lógica patriarcal voltado para a submissão e subordinação das mulheres, tendo como explicação a necessidade que o sexo oposto tem em dominar. A influência expressiva da cultura patriarcal nas relações contrárias de gênero, permanece até os dias atuais com exclusão das mulheres em vários contextos e pelo controle do homem sobre elas, por meio do seu posicionamento de pai ou de marido. Dessa forma, o entendimento do patriarcado constitui-se em estabelecer as diferenças que existem nas relações sociais entre homens e mulheres (Biroli, 2018; Alcântara et al., 2017).

Dessa forma, levando em consideração as transformações demográficas no Brasil, faz-se necessário o desenvolvimento de debates voltados para elaboração de estratégias relacionadas à saúde do idoso em todas as suas nuances, incluindo a sua sexualidade. Uma vez que, a velhice ainda é atrelada ao sinônimo de incapacidades, sendo a pessoa idosa vista como um ser assexuado, dotado de improdutividade, privado de sentir desejos, tornando ainda mais claro e evidente a prevalência de mitos e tabus sobre a temática (Gois et al., 2017).

Nesse sentido, a relevância deste estudo baseia-se no aumento contínuo da população idosa e nas suas necessidades de saúde em contexto da inclusão das diferenças de vivência com a sexualidade de homens e mulheres idosas, como parte da construção social de identidade advinda das experiências na relação de gênero evidenciadas nas histórias de vida. O estudo justifica-se pela importância de se trabalhar a sexualidade da pessoa idosa em seus diversos aspectos, as quais envolvem os significados das suas trajetórias e vivências, para assim desmistificar os tabus voltados para a sexualidade e envelhecimento. Além da afinidade com o público idoso e identificação com a disciplina presente na matriz curricular, a qual possibilitou a percepção das vulnerabilidades do homem e da mulher idosa nessa fase da vida.

Dado o exposto, o estudo apresenta a seguinte questão norteadora: Qual o sentido da memória de homens e mulheres idosas em vivência com a sua sexualidade, considerando as diferenças de gênero expressas nas experiências dos desafios, superações, opções morais, atitudes, percepções e sentimentos? Este artigo, tem como objetivo geral compreender o sentido da memória de homens e mulheres idosas em vivência com a sexualidade em construção sociocultural das diferenças de gênero; e como objetivos específicos descrever as experiências vivenciadas nas lembranças que expressam desafios/superações, opções morais, atitudes e sentimentos e analisar como se construiu as diferentes relações de gênero no envelhecimento e as repercussões na saúde do homem e mulher idosa.

\section{Metodologia}

Tratou-se de uma pesquisa qualitativa, descritiva de caráter exploratório, fundamentada na História Oral de Vida, que permite ao pesquisador desenvolver reflexões individuais e coletivas e elaborar concepções específicas, com maior riqueza de 
detalhes (Fialho et al., 2020). Dessa forma, através da compreensão do processo de construção da memória histórica, pode-se interpretar como os indivíduos vinculam passado e o presente, recordando a memória de homens e mulheres idosas nos relatos orais, a fim de registrá-las para uma posterior análise das suas experiências e vivências sexuais nas diferentes fases da sua vida (Lopes, 2019; Soares et al., 2016).

Desse modo, participaram da pesquisa nove pessoas idosas destes, quatro eram homens e cinco mulheres. Os idosos foram captados em uma Unidade de Saúde da Família (USF), sugeridos pela enfermeira coordenadora da unidade, que atenderam de forma voluntária ao convite para serem entrevistados em seus domicílios. Quanto às idosas, foram captadas a partir de um grupo de convivência "Descobrindo a Felicidade" vinculada à Associação de Amigos Grupos de Convivência e Universidade Aberta com a Terceira Idade (AAGRUTI), em um município do interior da Bahia parceira da Universidade Estadual do Sudoeste da Bahia (UESB).

Os critérios de inclusão para o estudo foi: ser idoso (a), estar em condições para expressar a linguagem oral e que tenham na sua história de vida a experiência vivencial da sexualidade; e os critérios de exclusão: idosos (as) que tinham comprometimento cognitivo e déficit de audição dificultando a comunicação.

O contato prévio com os participantes idosos, se deu por meio de um encontro com à enfermeira da USF enquanto que, as participantes idosas foram contactadas através de um encontro no grupo de convivência, informando-os acerca do objetivo da pesquisa. Em seguida, foi anotado o número do telefone das pessoas idosas que demonstraram interesse em participar do estudo e agendado posteriormente um encontro em locais escolhidos por estes.

Para a coleta de dados, foi utilizada a técnica de entrevistas abertas com roteiro semiestruturado, realizadas no período de outubro a novembro de 2019 e de fevereiro a março de 2020 em uma cidade no interior da Bahia, com duração média de 40 a 50 minutos, sendo gravadas com auxílio de um dispositivo celular e transcritas para análise posterior. Assim, para garantir a preservação da identidade dos (as) participantes utilizou-se codinomes de espécies de pássaros "Cardeal"; "Sabiá"; "PapaCapim"; "Bem-Te-Vi"; "Canária” para as mulheres idosas, e outros animais "Gato", "Touro", "Coelho", "Leão" para os homens idosos.

O tratamento e codificação do material seguiu o procedimento da História Oral de Vida, onde ocorreu a transcrição do oral para o escrito, seguindo as seguintes etapas: a) Transcrição exata do oral para o escrito; b) Textualização, que foi a transliteração da fala do(a) entrevistado(a) de modo espontâneo e na primeira pessoa; c) Transcrição, que se deu pela aproximação do sentido e intenção original do diálogo da entrevistada e que permite as conveniências das dimensões subjetivas; d) Conferência e autorização, que foi o período em que o texto final da entrevista foi lido e aprovado pelo(a) entrevistado(a); e) Retorno das histórias orais, momento em que os(as) participantes aprovaram a produção final da pesquisa (Meihy et al., 2007).

As informações adquiridas através das entrevistas, foram avaliadas conforme a Técnica de Análise de Conteúdo Temática, na qual possibilitou compreender os relatos além de seus significados imediatos, sendo possível realizar a codificação, a classificação e a obtenção de categorias, levando em consideração todo o arcabouço teórico, além do objetivo e problema do estudo (Bardin, 2011).

Nesse contexto, o estudo atendeu às normas estabelecidas pela Resolução 466/12, no qual foi submetido ao Comitê de Ética em Pesquisa com Seres Humanos da Universidade Estadual do Sudoeste da Bahia (CEP/UESB) e aprovado em parecer $\mathrm{n}^{\mathrm{o}}$ 3.637.693 e CAAE $\mathrm{n}^{\mathrm{o}}$ 22341219.5.0000.0055. Todas as pessoas idosas entrevistadas foram informadas quanto aos riscos, benefícios e objetivos do estudo, mediante a leitura e assinatura do Termo de Consentimento Livre e Esclarecido (TCLE). 


\section{Resultados}

O estudo contou com a participação de nove pessoas idosas, sendo quatro homens e cinco mulheres com idade entre 60 e 85 anos. Quanto ao estado civil, seis deles eram casados, um dos idosos era divorciado, uma idosa era viúva e outra solteira. No que diz respeito ao nível de escolaridade, profissão e religião, as mulheres eram todas alfabetizadas, católicas e participavam de um grupo de convivência para pessoas de mais idade, além de prestarem os serviços domésticos, enquanto aos homens, dois tinham ensino fundamental completo e dois possuía ensino médio completo, ao tempo que três eram aposentados e um servidor público; no que diz respeito a religião, eram católicos não praticantes.

Através dos resultados obtidos, notou-se que os idosos experimentaram e vivenciaram de forma distinta sua sexualidade em diversos momentos da sua história de vida envolvendo sentimentos, atitudes, comportamentos e desafios no seu processo de envelhecimento. Nesse contexto, os relatos dos tempos de memória dos homens e mulheres idosas em vivência com a sexualidade nas suas diferentes fases da vida, emergiram três categorias: 1- Memórias do homem e da mulher idosa: infância e adolescência; 2- Memórias do homem e da mulher idosa: fase adulta; 3- Memórias do homem e da mulher idosa: velhice.

A seguir serão apresentadas e analisadas as categorias emergentes do estudo.

\section{1- Memórias do homem e da mulher idosa: infância e adolescência}

Por meio das lembranças e experiências, os relatos das mulheres idosas nesse tempo de memória, expressam a ausência do diálogo no ambiente familiar, onde a comunicação era silenciosa, demonstrada muitas vezes através de sentimentos como o medo, vergonha, submissão patriarcal, obediência e respeito aos mais velhos e expressas nos atos escondidos por ser interpretada como uma atitude imoral.

Soma-se a esse fator na adolescência destas mulheres, as descobertas e conhecimentos sobre a sexualidade decorria de sensações e atitudes de curiosidade sem consciência do seu próprio corpo, como por exemplo, a menarca que era tida como tabu e a ideia da sexualidade limitada. Evidencia também, a soberania do pai no controle da sexualidade da mulher, a falta da aprendizagem e a exposição a riscos como uma gravidez não desejada as levavam para um casamento forçado, uma vez que, a honra da mulher era preservada, o que fica evidente a presença de uma cultura patriarcal. Destaca ainda, a convivência com a violência intrafamiliar e o abuso sexual de modo inconsciente expresso nas falas das mulheres.

“[...] não tinha muito diálogo com minha família sobre essas coisas ... ouvia as conversas de minha mãe com algumas tias, mas sempre escondido ... as meninas não falavam disso [...] fui sentindo uma sensação, que não tinha sentido antes, todas essas coisas eu contava as meninas da escola e eu fiquei sendo a mais experiente [...]" (PAPACAPIM)

“[...] não teve penetração, mas foi bom, fiquei com medo e cheguei em casa logo dizendo a minha mãe que estava grávida ... então ficava com medo ... meu pai obrigou a gente a se casar, foi aí onde minha vida mudou, na época eu não tinha 15 anos ainda, sem saber de nada da vida [...]” (PAPA-CAPIM)

"Tive que aprender e descobrir as coisas sozinha, naquele tempo falar sobre isso era motivo de discussão, tinha medo de falar e vergonha também ... já sentia umas coisinhas, mas sem saber do que se tratava ... que comecei a namorar, já quebrei logo o cabaço (virgindade) (risos)" (SABIÁ)

"A gente tinha aquele respeito às pessoas mais velhas, não falava sobre essas coisas, não tinha conhecimento nenhum né, ai desenvolvia assim mais pelo tempo, pela curiosidade, por escutar as coisas escondido [...]” (CARDEAL)

"Naquele tempo até a primeira menstruação era aquele tabu e a gente não sabia o que fazer, não sabia direito das coisas, depois pronto [...]” (CANÁRIA) 
"Tive infância e adolescência muito sofrida, minha mãe sofria muito com meu pai, que bebia muito, batia nela, em mim e meus irmãos [...] foi com meu tio, ele me tratava bem, cuidava da gente, comecei a me relacionar com ele eu tinha menos de 13 anos, descobri as coisas da vida com ele, principalmente essas em relação a sexo [...]” (BEM-TEVI)

Em contrapartida, os relatos dos homens idosos na infância e adolescência trazem a masturbação como meio de descoberta do prazer e aprendizagem da vida sexual desenvolvidas em grupos de amigos e também, como um refúgio para se saciarem. Assim, o processo de aprendizagem da sexualidade dos homens se deu também a partir das idas para os prostíbulos, onde, as mulheres profissionais do sexo assumiam o processo de educação sexual dos mesmos.

Contudo, os homens diferentes das mulheres tinham a liberdade de aprendizagem da sua sexualidade, no entanto, eles não tinham orientações e direcionamentos sobre a sexualidade no meio familiar, sob a condução das relações sociais e comunitárias, ficando notório o desconhecimento por parte deles sobre o assunto, como observa-se nas narrativas compartilhadas a seguir.

“[...] Eu com 12 anos, me lembro que estava no rio, com a turma né, foi ai a primeira vez que me ensinaram a me masturbar, aí comecei a me interessar pelo negócio [...] (LEÃO)

"[...] Nunca tive ninguém para me orientar, conheci a "punheta” (masturbação) na rua, desde cedo, e depois como eu disse o brega (prostíbulo) com os amigos, minha irmã que me criou nem ligava em tocar nesse assunto [...]" (GATO)

"Fiz muito na minha adolescência, masturbação, a gente não podia pegar as meninas para fazer o sexo, pois minha mãe sempre dizia quando eu comecei a ficar mais assim, não tire a filha de ninguém de casa, e isso nunca aconteceu comigo, era a preocupação de minha mãe era essa, meu pai não, nem ligava [...]" (TOURO)

“[...] Meu pai criava animal lá, égua, mula, cabra e eu fui faturando nesses animais na roça [...]13 a 14 anos, um amigo me levou para fubeca (profissional do sexo), naquele lugar cheio de mulher onde comecei o meu

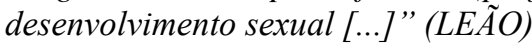

“[...] Tinha uma menina que trabalhava lá em casa, e meu pai levou ela, o que ela mais gostava de fazer comigo era essas coisas, me pegava, me botava em cima dela, foi de nove a 11 anos fazendo putaria mesmo com ela, na verdade ela fazendo comigo [...]" (TOURO)

Minha vida sexual começou como a de todo menino daquela época, eu fui o cara mais viciado em brega (prostíbulo) que eu conheci (risos)[...] quem me levou pra tirar a minha honra, como se diz quebrar meu cabaço, foi o finado, ele um dia encheu o fundo da caminhonete de rapazinho eu era o mais novo, sempre fui gaiato, lembro como hoje [...]" (COELHO)

“[...] Estava viciado já, qualquer coisinha o "binga (pênis) já subia”. Relação sexual com namorada eu só vim ter com minha esposa depois que eu casei, porque fora disso aí era só masturbação e brega (prostíbulo) [...]” (TOURO)

“[...] Quem era maior podia ficar até a hora que quisesse, a gente que era menor dependia de alguém levar, como eu mesmo, quem me levou foi um amigo mais velho, paguei a mulher pra mim e pra ele, trabalhei a semana toda, duro na roça pra poder ir [...] não utilizava camisinha, nem existia (risos), a gente não colocava a língua lá e nem elas colocavam a boca cá, era só a penetração, as mulheres que peguei estavam limpas [...]” (GATO)

“[...] Com a namorada não tinha nada, a vontade era tanta de ter logo o sexo e naquela época a gente tinha de respeitar a filha dos outros, tinha maior cuidado para não comer a filha de ninguém [...] "' (GATO)

\section{2- Memórias do homem e da mulher idosa: fase adulta}

As experiências da sexualidade vivenciadas por essas mulheres na infância e adolescência, trazem à tona memórias que se manifestam na fase adulta, as quais influenciaram no desenvolvimento e qualidade das suas relações afetivas nesse 
tempo. Os relatos apresentam as mudanças no relacionamento depois do casamento, em que passam a se dedicarem inteiramente aos afazeres domésticos e no cuidado com os filhos, as quais acabam por deixar de lado sua vida afetiva, revogando os seus desejos sexuais. Ademais, as falas retratam a aceitação da infidelidade em função do outro e ainda a sujeição à pratica sexual involuntária a fim de evitar brigas.

Notou-se nas narrativas compartilhadas, que o começo de uma nova relação proporcionou a descoberta do prazer o que não era possível no seu último casamento. Por outro lado, o início de um novo casamento associa-se ao sentimento de solidão pelo medo de ficar sozinha. A religião mencionada em um dos relatos, se configura como um lugar de refúgio, no intuito de amenizar o sentimento de culpa por atitudes e experiências sexuais vivenciadas na infância e adolescência.

"[...]Depois que casei e tive os filhos, algumas coisas mudaram, fiquei mais dedicada a casa, aos meninos e esqueci de procurar o marido, mas toda noite ele tava lá, querendo umas coisinhas, as vezes eu negava, outras vezes eu cedia, se eu fosse fazer a vontade dele era umas três ou quatro vezes no dia [...]" (SABIÁ)

“[...] Quando casada fui aprender as coisas da vida e não foi fácil, no começo ele me tratava bem, a gente namorava, mas só era nas coxas, depois que abriu um brega (prostíbulo) na cidade, ele mudou, começou a me tratar mal, querer me agredir, pior fase da minha vida ... Ele chegava em casa bêbado, com cheiro de perfume de mulher, até que um dia queria me pegar a força e eu saí correndo [...]" (PAPA-CAPIM)

“[...] percebi ele estranho, descobri nisso uma traição, mas na época nem me importei, para ele não ficar chateado eu deixava, fiquei até em paz por um tempo [...]” (SABIÁ)

"[...] quatro anos depois conheci Curió, que ficou comigo até a morte, com ele descobri o prazer e foi meu primeiro homem que eu tive penetração e tive prazer, pense que coisa boa viu (risos) [...]” (PAPA-CAPIM)

“[...] aí conheci meu marido, que está comigo até hoje, eu já tava em uma idade pouco avançada para casar de novo, mas não queria morrer só, aí casei com ele [...]” (BEM-TE-VI);

“[...] Já construí minha família, eu não quis mais me relacionar com ninguém, fui casada durante 43 anos, nos conhecemos em parquinho, era namoro de mão dada, de ir nas festas de igrejas, as quermesses, dançava junto [...]" (CARDEAL)

“[...] Depois da morte de meu tio me revoltei, comecei a namorar, tive vários casos, casei, tive um filho, namorei outros rapazes, mas nessas idas e voltas, eu sempre permanecia na igreja, era o meu refúgio, depois da experiência de vida sexual com o meu tio desde criança, tinha que ir [...]” (BEM-TE-VI)

Para os homens idosos, na fase adulta, foi possível perceber nos relatos que o sexo se manifesta a partir das infidelidades e da necessidade de buscar a satisfação com mulheres na rua para realizar seus desejos sexuais, mas sem abrir mão da sua esposa em casa. Além disso, os relatos exteriorizam a falta de compreensão do homem com sua esposa no período do puerpério, expressando os seus desejos sexuais durante esse período, e o descaso sobre o uso de preservativos durante as relações.

Nas falas dos entrevistados, percebe-se o receio da ausência da prática sexual com penetração em meninas moças e virgens, a fim de não correr o risco de engravidá-las e serem submetidos a um casamento indesejado, o que fortalece para a cultura patriarcal e falta de diálogo entres pais e filhos. Além disso, nos relatos a seguir fica evidente a responsabilidade da mulher por uma gravidez indesejada.

“[...] Dos 17 até a idade de ter a primeira filha eu tive muitas namoradas, algumas tinha relação sexual e outras não [...] Eu faturava nas pernas das meninas de menor, "gozar nas coxas”, eu era viciado, pra não engravidar pra não ter problema, se era de maior aí a gente tinha relação [...]” (LEÃO) 
“[...] Toda noite a partir das oito horas você já me encontrava no carrapato, viciei, não tem como negar não, se era bom [...] as relações com essas mulheres era só penetração, até o dinheiro elas não pegavam das nossas mãos, a gente deixava encima da banca do lado da cama, e elas nos lavava com uma bacia de água [...]” (TOURO)

“[...] Sempre tive a necessidade de ter várias mulheres na rua, mas só me satisfazia com a mulher de casa, passava a noite toda com mulher na rua, mas quando chegava em casa tinha que ter relação com a minha mulher [...]” (LEÃO)

“[...]A namorada com quem casei, a gente ia para as festinhas e dançava muito, eu já sabia dançar que tinha aprendido no brega (prostíbulo), e ela dançava muito bem. Mas nesse tempo eu dava umas investidas, mas não era correspondido [...]” (TOURO)

“[...] O tempo passa e quando chega certa idade, o cansaço do dia a dia do trabalho, vai atrapalhando, a gente vai colocando a culpa no trabalho, mas na verdade é a idade pesando [...] acho que eu comecei a perder mais a força de 50 para 55 anos, não é que despencou não, mas o fogo vai ficando mais brando, fogo baixo chamado né? (risos) $[\ldots] "(G A T O)$

“[...] Fui caminhoneiro 15 anos na estrada já comi muita mulher, nunca peguei uma doença, dava sorte, naquela época não existia camisinha, a gente comia no pelo mesmo (risos) [...]” (COELHO)

"[...] quando a mulher tinha filho e tinha resguardo, eu esperava passar o tempo, mas dava um pulo fora, não aguentava, tava viciado, porque bicho atrapalhado é o homem viu, que está em cima até o dia da mulher parir [...]" (TOURO)

"[...] A conversa desse assunto em casa com minhas filhas, ficava sempre com minha esposa, que conversava, até por serem mulher, nunca toquei nesse assunto com minhas filhas [...]” (TOURO)

\section{3- Memórias do homem e da mulher idosa: velhice}

$\mathrm{Na}$ fase da velhice, através do sentido de memória das mulheres idosas, foi possível perceber e reconhecer as mudanças expressas pelas idosas sobre seu corpo advindas com o tempo e como essas transformações influenciaram na sua sexualidade, como a diminuição da libido, perda da lubrificação e dores na região íntima. Observa-se nos relatos, que algumas das idosas procuram por solução demonstrando motivação em busca de melhorias para os seus relacionamentos. No entanto, o modo como elas enfrentam essas transformações é singular e característico de cada uma, principalmente vivenciando a viuvez.

Ademais, percebeu-se sentimento de vergonha ao abordar a temática, visto que, a sexualidade nessa fase da vida é recheada de estigmas e preconceitos a partir de uma perspectiva sociocultural. Além disso, a inclusão da tecnologia, uso do celular para obtenção de informações na internet, a utilização de produtos eróticos e o ato de se masturbar para se satisfazer, é citado nas falas das idosas como uma forma de redescobrir o prazer e conhecer seu próprio corpo. Por outro lado, observa-se nas falas a permanência da anulação dos seus desejos e prazeres, sendo submetidas a satisfazer os desejos do seu parceiro esquecendo de si mesma, assim como, a aceitação da infidelidade e a presença da violência contra a mulher.

Os relatos expressam também, a falta de apoio por parte dos profissionais de saúde, apontando a necessidade de ter diálogos voltado para a temática, a fim de proporcionar um melhor enfrentamento para lidar com as limitações decorrentes das modificações do corpo ao longo dos anos.

"[...] Hoje em dia sinto vontade, mas não é como antigamente, a idade chegou, as coisas foram mudando, meu corpo principalmente, mas eu convivo bem com ela, a idade virou minha aliada [...]” (BEM-TE-VI)

“[...] Eu fico meio assim em falar dessas coisas, porque não costumo falar muito sobre isso, ainda no tempo de hoje a gente sendo velha [...] depois que fui ficando velha, percebi que as coisas foram mudando, a gente fica sem muita vontade, com vergonha de falar que tem vontade, com dor na parte íntima, mas eu sempre procurei solução [...]" (PAPA-CAPIM) 
“[...] Ele também foi ficando velho, as coisas começaram a despencar e demorar para subir, mas eu não falava nada, sempre tentava dar um jeito [...] mas homem tu sabe como é, mesmo impotente se sentem o machão, eu deixo até hoje $[\ldots]$ ". (SABIÁ)

“[...] Tenho na verdade é que agradar ele, satisfazer as vontades dele, eu nem ligo mais, pra mim tanto faz, deixo mesmo para evitar briga, perdi o interesse nele em relação a essas coisas [...] está pensando que ele deixou de ir procurar coisa na rua, deixou não, o povo me conta, ele dar dinheiro para as meninas nova, em troca não sei de quê, porque as coisas já não funcionam mais, eu nunca reclamei [...]" (SABIÁ)

"[...] Eu mesmo tenho muito fogo ainda, procuro sempre que dá fazer uma coisinha, ter prazer, porque eu não estou morta [...] hoje com as mudanças do corpo a gente fica mais ressecada, mas eu sempre tenho aqui em casa um lubrificante, um óleo, uma pomada, uma coisinha, comprei até um golfinho que vibra (risos), não posso ficar na vontade também né [...]" (CANÁRIO)

“[...] Não sou de tá ligando e insistindo, devido a situação dele, quando eu quero, eu deito e me aproveito sozinha. [...] quando vem bem, quando não vem me viro sozinha, mas tem dias que não tô afim, aí fico na minha, hoje entendo as limitações do meu corpo, porque a idade chegou né, tenho que me preservar [...]" (CANÁRIO)

“[...] O homem se transformou, hoje é todo grosso, me trata frio, quer fazer as coisas a força, toma aquele remédio azul, deu para beber, aí chega em casa bêbado, se eu deixar quer até me bater, fica me procurando na cama a força, eu fico sentida [...]" (BEM-TE-VI)

"[...] Na minha vida eu nunca deixei de fazer nada, só sofri no início, quando era jovem, mas eu fiquei madura e vivi muita coisa, graças a Deus [...] depois do celular a vida da velhinha aqui melhorou, pesquisei as coisas e tinha prazer e claro que ia descobrindo meu corpo [...] eu não consigo ter penetração, só fazemos umas coisinhas antes [...]" (PAPA-CAPIM)

“[...] Tinha que ter remédio pra gente mulher também [...]. Fazer umas rodas pra gente conversar, dar dicas para enfrentar as dificuldades e a gente que já ta na idade saber se adaptar com isso [...]” (SABIÁ)

“[...] Sou viúva há 11 anos, é normal, não tenho intenção de ter ninguém em minha vida não, depois dele, a chama se apagou dentro de mim[...] eu vivo muito na igreja e deixei de lado isso de mulher, de pensar nessas coisas, não me faz falta e acho que por isso não tenho isso de pensar sobre sexo e nem ter vontade, deixei pra lá, sei que me anulei das coisas[...]. Existe também a falta de interesse, ainda mais do pessoal em minha idade e falta apoio, o povo gosta de banalizar essas coisas ... os profissionais de saúde eles não falam sobre isso, isso tem que mudar, mas até gosto [...]" (CARDEAL)

Assim como as idosas, os idosos nessa fase da vida começaram a perceber as mudanças que ocorrem em seu corpo ao longo dos anos. Nas falas é possível identificar as dificuldades acerca da sua função erétil visto que, com o envelhecimento a sua disposição sexual também sofreu alterações e adaptações.

Nos relatos, observa-se que os idosos associam sua impotência ao cansaço, bem como, à diminuição na frequência das suas atividades sexuais com a indisposição da sua cônjuge ou mesmo advindas das doenças crônicas não transmissíveis (DCNT). Expressam sentimentos de raiva e vergonha pela perda da sua virilidade, justificando-as como consequências dos acontecimentos e estresses da rotina, a qual resulta em brigas e desentendimento na relação conjugal. Outrossim, nota-se nas falas a prática da masturbação, para substituir a falta da atividade sexual e até mesmo o uso de estimulantes para melhorar a disfunção erétil.

Entretanto, ainda que o desempenho e a prática dos idosos não seja a mesma como nas outras fases da vida, os relatos constatam a presença do desejo sexual, e a procura de se manterem ativos sexualmente seja com sua esposa ou com outras relações extraconjugais.

“[...] As mudanças eu comecei a perceber depois dos 50 anos e quando a gente deixa de fazer, parece que a coisa vai diminuindo, esquece ... e estar sempre em dias, faça todos os dias para a você ver uma coisa, que você não aguenta ver a mulher na cama, se é pra tomar banho você quer está junto, você quer estar cutucando [...]" (TOURO) 
“[...] As mudanças começam com a distância, a gente demora mais para procurar a mulher, isso no começo, e mais pra frente o corpo não responde mais na hora que a gente quer, isso dá uma raiva até vergonha [...] com o tempo um vai acostumando com as mudanças, isso se a mulher for companheira, e entender [...]” (GATO)

“[...] Percebi um pouco de mudanças, me sentia cansado, achava que era por causa da diabetes, o povo diz que essa doença acaba com o homem, mas o "binga" (pênis) passou a demorar mais pra subir, a descer mais ligeiro, isso em algumas relações [...]" (LẼ̃O)

“[...] a gente já está ficando velho, e agora se der pra dar uma, a gente dá, mas se não der pra comer, dar pra "chupar" [...] fico em casa, se aparecer alguém fácil eu quero e ainda faço alguma coisa, mas se não aparecer eu fico sossegado na vontade, eu me masturbo e vou levando a vida [...] em 2017 eu fui anotar quantas "punheta" (masturbação) eu batia num ano, deu 1.117, mas aí depois fui parando a gente já está ficando velho [...]” (LEÃO)

"[...] porque quando a mulher viaja eu fico muito só e eu não aguento ficar sem fuder (relação sexual) não, mas é coisa civilizado sabe [...] eu tomei um desses remédios umas vezes porque o bicho aqui estava preguiçoso sem querer trabalhar, aí teve umas duas vezes aí que a mulher passou a mão e o bicho do jeito que tava dormindo ficou, a mulher veio me dizer coisa, aí eu tomei umas vezes [...] eu descobrir o que tesão de homem é cabeça fria, se o cabra estiver despreocupado tudo funciona e ainda mais que a gente vai ficando mais velho, mais cansado, então qualquer coisa afeta [...]" (COELHO)

“[...] Eu digo assim, 50\% das brigas dos casais é por causa do sexo, porque o homem demora mais que a mulher, estou com 74 anos e ainda gosto muito [...]” (TOURO)

\section{Discussão}

As vivências dos idosos obtidas por meio dos relatos referentes à sua sexualidade em história de vida, se expressam em um tempo de memória através das lembranças e experiências. Em que a "consciência é memória, uma vez que, o passado se conserva e continua no presente. No entanto, a consciência precipita o futuro, criando expectativa para uma futura ação" (Bergson, 2006, p. 116). Em vista disso, as lembranças manifestam as diferentes relações de gênero, sendo compreendidas como uma construção histórica, em que a ideia da cultura patriarcal estabelece modos de compreender o desenvolvimento humano do homem e da mulher idosa.

Desse modo, mediante a análise dos relatos, notou-se durante a fase de infância e adolescência da mulher idosa a ausência do diálogo no ambiente familiar a respeito da sexualidade. No qual, as descobertas do próprio corpo passam ser de forma individual ou mesmo compartilhado às escondidas em grupo já que, tinham uma educação carregada de tabus e princípios morais com relação a sexualidade e de gênero, as quais distinguiam as atitudes para homens e mulheres.

Por conseguinte, os relatos das mulheres idosas nesse tempo de infância corroboram com o estudo realizado com mulheres portuguesas maiores de 65 anos, onde relataram a falta de comunicação com a família sobre a sexualidade, assim como, a propagação de mitos, preconceitos e o entendimento biológico dividido em relação aos modelos de gênero na submissão e omissão das mulheres. Dessa maneira, essa falta de diálogo gerou obstáculos nas relações afetivas e íntimas em outras fases da vida uma vez que, a educação que lhes eram oferecidas baseavam-se na dicotomia de gênero (Queiroga, Magalhães \& Nogueira, 2018).

Diante disso, "a socialização primária corresponde a primeira etapa de socialização em que o sujeito experimenta. Etapa essa, que envolve valores as quais proporcionam a inclusão do indivíduo na sociedade. O início desse processo se dá nos primeiros anos de vida, sendo a família o pilar central para essa inclusão", a qual podemos observar nas falas dos homens e das mulheres idosas (Silva et al, 2015, p. 36). No entanto, esse processo de aprendizagem acontece de forma desigual para os homens e mulheres.

Posto que, os homens diferentes das mulheres, tinham a liberdade de aprendizagem da sua sexualidade. Os idosos no período da sua infância e adolescência, desenvolveram a sua sexualidade por meio de aprendizados e experiências advindas de amigos ou de familiares próximos, como as práticas sexuais e de masturbação e as convivências em bordéis as quais 
simbolizaram o início da sua vida sexual.

Assim, através das falas dos participantes, verificou-se que o ato de se masturbar era também um refúgio, já que naquele tempo era proibido terem relações sexuais com as meninas antes do casamento, demonstrando respeito com as mulheres mais jovens e suas famílias. Isso porque, essas mulheres eram vistas como moças de família, respeitá-las estava associado a não correr o risco de engravidá-las e como consequência do prazer, terem um casamento antecipado. Ao mesmo tempo, percebe-se o desrespeito com as mulheres tidas com "fáceis", sendo julgadas e menosprezadas pela sociedade por vivenciarem sua sexualidade e experiências.

A saber, naquele tempo as famílias valorizavam a importância do casamento, da virgindade e do papel da mulher voltado para maternidade e cuidadora do lar, assim como, da fidelidade. Essas concepções se associam com a história da sexualidade feminina no Brasil, onde preservava-se uma moral baseada em valores religiosos em que as mulheres renunciavam o seu prazer antes do casamento pois, caso essas "normas" fossem contrariadas, as mulheres sofriam com a culpa, preconceitos, desonras e punições (Fernandes-Eloi et al., 2017).

Ademais, a presença preponderante do patriarcado faz-se presente desde o começo da vida das mulheres idosas. Este pode ser compreendido como um sistema político-cultural de opressão, apresentado através da dominação de forma simbólica dos detentores de poder (homens) sobre as mulheres e demais seres subjugados (Burckhart, 2017). Deste modo, demonstra-se as desigualdades entre homens e mulheres dentro da sociedade e nas suas relações sociais.

As falas revelam que na infância, os homens idosos já trabalhavam e convergiam suas economias para as práticas sexuais nos bordéis, onde, vivenciavam sua sexualidade com mais liberdade ao se relacionar com as mulheres tidas como profissionais do sexo. Dentro dessa perspectiva, percebe-se que a presença do capitalismo remete a uma manifestação simbólica de poder, onde o domínio masculino concentra-se nas práticas que colocam as mulheres em situações de proibição, como por exemplo, frequentar determinados lugares ditos como espaços específicos para homens, sendo assim, não existe uma formação social "patriarcado" separado do "capitalismo" (Hirata, 2018).

Desta forma, ficam notórias as diferenças nos comportamentos nas relações masculinas e femininas como também, a forma que ambos descobrem e expressam sua sexualidade. Os relatos das mulheres idosas foram evidenciados por sentimentos de medo, desconhecimento, vergonha e culpa, marcando o início da sua vida sexual, ao contrário dos homens que tinham permissões e liberdade para poder desfrutar da sua sexualidade.

Convém evidenciar que os achados da literatura destacam a posição priorizada que os homens tinham sobre sua sexualidade e o seu poder nos relacionamentos (Fernandes-Eloi et al., 2017; Sousa \& Sirelli, 2018). Posto isto, a representação do feminino e do masculino numa concepção de relações de gênero, retoma a um contexto histórico, onde o patriarcalismo é fortemente presente o que solidifica as questões de poder, a qual a posição de inferioridade volta-se para as mulheres.

Destarte, a educação repressora recebida pelas mulheres idosas na infância e adolescência provocou efeitos nas relações afetivas durante o período da fase adulta. As mulheres idosas procuraram se dedicar aos filhos, família e as atividades domésticas, abdicando das suas necessidades e desejos sexuais. Nesse contexto, os tabus e o desconhecimento acerca da sexualidade decorrente da ausência de informações, colaboram para o desenvolvimento de desigualdades, sentimentos de medo, culpa, dúvidas, hesitações, vulnerabilidades e submissão (Nardelli et al., 2017; Queiroga, Magalhães \& Nogueira, 2018).

Corroborando com essa ideia, outros estudos apresentaram o afastamento dos desejos sexuais das mulheres em prol da maternidade e o papel de cuidadora. Em contrapartida, no que tange aos homens, observaram os efeitos da educação e da socialização clássica de gênero, além das premissas a respeito da sua virilidade.

A liberdade continuada associada com a presença da infidelidade durante a fase adulta, expressa a dupla moral sexual em que os homens idosos mantêm uma maior liberdade das suas vivências sexuais em relação as mulheres idosas, a qual 
buscam por outras relações extraconjugais. Tais acontecimentos, condizem com o que Medeiros (2019), traz acerca do modelo tradicional de família, que concede aos homens a liberdade sexual para continuar com relações fora do casamento, no entanto, delimitam e proíbem a liberdade da sexualidade da mulher, demandando das mesmas fidelidade e respeito.

Frisa-se que as construções sociais desiguais de gênero ao longo dos anos, ratificaram o pensamento de submissão voltado para as mulheres, enfatizando a representação delas para o cuidado e maternidade. Além disso, retrata que esses acontecimentos coincidem com o modelo tradicional da masculinidade hegemônica, o que fortalece a concepção de características como virilidade, agressividade, poder, estar como o provedor da família e a necessidade do prazer sexual (Zanello et al., 2015). Nesse sentido, deve-se dizer que a existência dessas desigualdades de gênero e do poder destinados aos homens, estimulam a violência doméstica contra as mulheres, sendo muitas vezes naturalizadas pelas mesmas a fim de evitar desentendimentos nas suas relações conjugais.

Com isso, os relatos dos homens e mulheres idosas nesse tempo de memória, além de afirmarem a naturalização no que diz respeito às relações desiguais de gênero, trazem efeitos que influenciam na autoestima, bem-estar e sexualidade da mulher idosa, uma vez que, diferente delas, os homens vivenciavam sua sexualidade sem muitas limitações, assegurando a sua sexualidade com práticas de infidelidade durante o casamento (Medeiros, 2019; Sousa et al., 2018; Zanello et al., 2015).

Durante a fase da velhice, percebe-se que os homens e as mulheres idosas identificam as mudanças corporais advindas com o tempo. Estudos ressaltam que os surgimentos dessas mudanças são influenciados por outros determinantes além dos biológicos, como experiências anteriores, a liberdade de viver a sexualidade, a história de vida, relacionamentos afetivos, educação, entre outros (Crema et al., 2021).

Os homens e as mulheres idosas frente a essas transformações, experimentam um processo de adaptação que influenciam nas opiniões acerca da sexualidade e gênero. Nas mulheres idosas, as transformações físicas e fisiológicas do processo de envelhecimento, como a diminuição da libido, lubrificação natural, feminilidade e frequência das relações sexuais, influenciam na imagem e na sua autoestima (Cabral et al, 2019). Nessa perspectiva, as mudanças que ocorrem nessa fase da vida, é permeada de dificuldades em função das desigualdades de gênero e dos preconceitos sociais que condenam a sexualidade na velhice, as quais interferem de forma negativa no que diz respeito à percepção e o controle dessas transformações.

Assim, as mudanças corporais nas idosas, associadas a uma cultura que glorifica o corpo jovem, recriminando o velho, só serve para ratificar o pensamento que elas têm de não serem mais atraentes e desejáveis durante a velhice (Oliveira, Neves \& Silva, 2018). Além disso, sob o ponto de vista simbólico, as mulheres idosas são colocadas em posição de inferioridade no que diz respeito a criação da sua imagem corporal, visto que, a sociedade faz jus ao corpo jovem, validando o tabu da sexualidade na velhice como seres assexuados, desprovidos de desejo e anseios (Soares et al., 2021).

Nessa perspectiva, o processo de envelhecimento está associado a novas experiências e diversas mudanças, trazendo reflexões sobre as distintas relações de gênero. As pessoas idosas também vivenciam e experimentam transformações ao chegar nessa fase da vida, no qual encontram dificuldades na prática sexual dentro do seu relacionamento conjugal, com a diminuição da sua virilidade associada a impotência.

Tendo em vista que, os homens idosos ao tempo que mantém vivos os seus desejos sexuais, vivenciam as dificuldades relacionadas a diminuição da sua função erétil e dessa forma, desencadeiam sentimentos de angústia, decepção, frustração e medo de fracassar. Assim, a disfunção erétil fere a masculinidade do homem e essas mudanças fazem com que os mesmos percam sua vivacidade daquilo que socialmente os fazem se sentir "homem", pois, socialmente foi construído a ideia de que para afirmarem sua sexualidade, os homens precisariam manifestar sua virilidade através de uma sexualidade erétil e penetrante (Gewirtz-Meydan et al., 2019; Soares et al.,2021).

Por sua vez, verifica-se que os desejos sexuais ainda se fazem presente durante a fase da velhice, no entanto, essa fase 
ainda perpassada por muitos estigmas e preconceitos, uma vez que, nessa etapa da vida as limitações passam a serem maiores, em função das alterações fisiológicas que surgem. Nos relatos das mulheres idosas, observa-se que, apesar de terem seus desejos sexuais mantidos, apresentam dificuldades em vivenciar sua sexualidade de forma ativa, em razão das traições e experiências negativas nas relações afetivas e sexuais passadas, além de serem de uma geração onde o sexo só poderia ocorrer depois do matrimônio.

Nesse sentido, as mulheres acabam por não vivenciar de forma livre a sua sexualidade em decorrência dos estereótipos e estigmas sociais, devido a uma sociedade machista e sexista, onde o papel da mulher é limitado, voltado para à educação dos filhos e os cuidados domésticos (Oliveira et al., 2018). O que se assemelha ao pensamento de Cabral et al. (2019) em que, o entendimento da sexualidade é baseado muitas das vezes somente no conceito de relação sexual, a qual é formada desde o período da adolescência, onde a sexualidade era somente praticada no casamento com o intuito de reproduzir.

De um ponto de vista sociocultural, as mulheres são reflexo de reprodução e cuidado, sendo ensinadas a satisfazer o sexo oposto, anulando os seus próprios desejos sexuais, especialmente durante a velhice. Logo, percebe-se que a sexualidade da mulher era voltada para obediência diante do seu marido, demonstrando as diferenças nos papéis sociais do homem e da mulher idosa (Soares et al., 2021; Fernandes-Eloi et al., 2017; Mendonça et al., 2020).

Destarte, os paradigmas impostos socialmente apontam que para o homem ser viril, o mesmo precisa demonstrar seu poder perante as mulheres, garantindo sua eficiência na prática sexual através do bom funcionamento erétil. Ademais, observou-se nos relatos que muitos dos idosos eram adeptos ao uso de pílulas com o intuito de combater a sua impotência sexual. De acordo com a literatura, os homens idosos nessa fase da vida, demonstram a necessidade de continuar vivenciando a sua sexualidade no que diz respeito a prática do ato sexual (Soares \& Meneghel, 2021).

Assim como os homens, as mulheres idosas, procuraram vivenciar o seu prazer durante esse processo de envelhecimento, buscando reafirmar seus desejos sexuais através do uso do celular, mantendo-se informadas através da internet, ou pela aquisição de produtos eróticos e masturbação visando conhecer o seu próprio corpo e se satisfazerem sexualmente. Tal fato, está associado com as oposições realizadas pelos movimentos feministas, a qual buscava a autonomia das mulheres e a igualdade feminina, que envolve a busca pelo seu prazer sexual (Medeiros, 2019; Zanello et al., 2015).

Sendo assim, numa compreensão de gênero, os homens expressam seu pensamento acerca da sua sexualidade centrada mais no ato sexual propriamente dito, no entanto, com as alterações durante o processo de envelhecimento, os mesmos sentem as limitações que essas mudanças trazem. Em contrapartida, as mulheres idosas apresentaram uma interpretação da sua sexualidade diferente dos homens, uma vez que, as mesmas, tiveram uma educação pautada na rigidez, onde os padrões de gênero ditavam o que era moral e imoral, as quais, eram socializadas para satisfazer as vontades do sexo oposto, anulando os seus próprios. Desta forma, compreendem a sexualidade como uma condição própria das outras fases que antecede a velhice, deixando de dar importância a sua sexualidade e revogando os seus desejos e prazer (Oliveira et al., 2018).

Mediante essas considerações, os resultados propiciam informações relevantes acerca da sexualidade de homens e mulheres idosas. A ausência de informações, vergonha e os tabus influenciam na qualidade da sexualidade dos idosos, consequentemente dificultando a abertura deles em dialogar com os profissionais de saúde, especialmente o enfermeiro. Deste modo, é importante enfatizar que a sexualidade e o processo do envelhecimento estão diretamente relacionados ao cuidado do profissional de enfermagem, dado que, o mesmo está na linha de frente nos diversos domínios de cuidado, incluindo a assistência à saúde e sexualidade da pessoa idosa.

Sendo assim, é de grande relevância que estes profissionais passem confiança para os idosos, promovendo o vínculo entre paciente e enfermeiro. Portanto, é imprescindível a inclusão de discussões por parte destes profissionais, frente à sexualidade do homem e da mulher idosa. 


\section{Considerações Finais}

Diante dos relatos dos homens e mulheres idosas expressos em tempo de memória, foi possível compreender através das suas lembranças os significados e vivências acerca da sua sexualidade e as diferentes relações de gênero em seus relacionamentos conjugais. A presença de uma educação inflexível, onde, não havia um diálogo intrafamiliar e informação sobre a sexualidade foram apresentadas nas falas dos participantes. Além disto, as relações desiguais de gênero alicerçadas de uma cultura patriarcal.

Por sua vez, as questões desiguais de gênero quanto à divisão de papéis sociais para homens e mulheres foi ratificado partindo de uma perspectiva histórica, demonstrando assim, os papéis ditos próprios para as mulheres. Tais como, a maternidade, cuidadora do lar, reprodução, resignação e anulação dos seus desejos e prazeres ao contrário dos homens, que detém o poder e é visto como líder e provedor da família, a qual possui autoridade moral com total liberdade das suas escolhas e atitudes, em especial para vivenciar sua sexualidade.

Assim, o processo do envelhecimento adjunto com as experiências da sexualidade dos homens e mulheres idosas foram revelados mediante as mudanças ocorridas ao longo das suas vidas, tanto no meio social quanto no pessoal, com a aprendizagem nos seus relacionamentos afetivos e informações advindas socialmente. Posto isto, apesar de a sociedade estigmatizar a sexualidade e a velhice, a relação entre essas duas categorias ultrapassa a ideia limitada de que o idoso é um ser assexuado e que a velhice é sinônimo de incapacidade.

Por essa razão, é fundamental que os profissionais de enfermagem busquem o conhecimento necessário, de modo que compreendam a sexualidade dentro do processo do envelhecimento, suas vulnerabilidades e concepções mediante as vivências e experiências dos idosos. Promovendo uma relação de confiança mútua, no qual pode facilitar e estimular os idosos a compartilharem suas histórias de vida relacionadas à sua sexualidade, sendo isentos de preconceitos e tabus, visando uma melhora da integralidade do cuidado, na valorização da autoestima e no bem-estar biopsicossocial da pessoa idosa.

Diante disso, é necessário que haja a promoção e educação em saúde frente as próprias experiências dos idosos, uma vez que, a sexualidade é um elemento importante para o processo do envelhecimento, apresentando uma nova perspectiva de saberes e vivências quanto à sexualidade. Sendo que, atua nos seus comportamentos, pensamentos e ações, dessa forma rompendo com os as normas sociais que reflete estigmas e preconceitos com relação a velhice e a sexualidade.

A saber, a pesquisa apresentou limitações quanto a busca pelos artigos no banco de dados, apresentando uma escassez de publicações que abordasse uma compreensão mais profunda acerca das relações entre sexualidade e envelhecimento correlacionando com as diferenças de gênero. Portanto, dificulta uma melhor compreensão acerca da temática: envelhecimento, sexualidade e suas questões de gênero. Sugere-se a elaboração de planejamento em educação em saúde com ações direcionadas sobre a temática da sexualidade para a população idosa, a fim de ampliar o conhecimento e atitudes relacionadas à promoção da saúde sexual dos idosos, como também, a implementação de estratégias de educação permanente no âmbito da atenção básica para à prática qualificada dos profissionais de enfermagem.

\section{Agradecimentos}

Agradecemos as contribuições das pessoas idosas participantes voluntários desta pesquisa, que foram fundamentais para a construção do estudo. Assim como, à Secretaria Municipal de Saúde de Jequié pela autorização da coleta, e o grupo de convivência a qual é ligada à Associação de Amigos Grupos de Convivência e Universidade Aberta com a Terceira Idade (AAGRUTI), em parceria com a Universidade Estadual do Sudoeste da Bahia (UESB). 


\section{Referências}

Alcântara, P. P. T., Peixoto, C. L., \& Silva, A. M. S. (2017). As relações patriarcais de gênero na família: influência da mídia televisiva. Holos, 7, $270-277$.

Bardin, L. (2011). Análise de conteúdo. São Paulo: Edições 70.

Bergson, H. (2006). A lembrança do presente e o falso reconhecimento. Trans/Form/Ação, 29, 95-121.

Biroli, F. (2018). Gênero e desigualdades: limites da democracia no Brasil. Boitempo Editorial.

Burckhart, T. R. (2017). Gênero, dominação masculina e feminismo: por uma teoria feminista do Direito. Revista Direito em Debate, 26 (47), $205-224$.

Cabral, N. E. D. S., Lima, C. F. D. M., Rivemales, M. D. C. C., Souza, U. S. D., \& Silva, B. M. C. D. (2019). Compreensão da sexualidade por idosas de área rural. Revista Brasileira de Enfermagem, 72, 147-152.

Crema, I. L., \& Tilio, R. D. (2021). Gender and sexuality in intimate relationships: interpretation and experiences by elderly women. Psicologia: teoria e prática, 23(2), 1-22.

Fernandes-Eloi, J., Dantas, A. J. L., Sousa, A. M. B. D., Cerqueira-Santos, E., \& Maia, L. M. (2017). Intersecções entre envelhecimento e sexualidade de mulheres idosas. Saúde \& Transformação Social/Health \& Social Change, 8 (1), 61-71.

Fialho, L. M. F., Junior, V. R. D. S. B., Monte, R. S., \& Brandenburg, C. (2020). O uso da história oral na narrativa da história da educação no Ceará. Práticas Educativas, Memórias e Oralidades-Rev. Pemo, 2 (1), 1-13.

Gama, A.V. (2021). Sexualidade e Envelhecimento. Crm/To- Conselho Regional de Medicina do Estado do Tocantins, [s.d]. <http://www.crmto.org.br/index.php?option=com_content\&view=article\&id=21398:sexualidade-e envelhecimento\&catid=46:artigos\&Itemid=495>.

Gewirtz-Meydan, A., Hafford-Letchfield, T., Ayalon, L., Benyamini, Y., Biermann, V., Coffey, A., ... \& Zeman, Z. (2019). How do older people discuss their own sexuality? A systematic review of qualitative research studies. Culture, health \& sexuality, 21(3), 293-308.

Gois, A. B., dos Santos, R. F. L., da Silva, T. P. S., \& de Aguiar, V. F. F. (2017). Percepção do homem idoso em relação a sua sexualidade. Enfermagem em Foco, 8(3).

Hirata, H. (2018). Gênero, patriarcado, trabalho e classe. Revista Trabalho Necessário, 16(29), 14-27.

Lopes, A. D. P. C. (2019). Legislação e processos educativos: A constituição da escola primária no Piauí (1845 a 1889). Educação \& Formação, 4(10), 50-65.

Medeiros, L. F. D. (2019). A inter-relação entre transtornos mentais comuns, gênero e velhice: uma reflexão teórica. Cadernos Saúde Coletiva, $27,448-454$.

Meihy, J. C. S. B., \& Holanda, F. (2007). História oral: como fazer, como pensar. Editora Contexto.

Mendonça, E. T. M., Cunha Araújo, E. da, Botelho, E. P., Polaro, S. H. I., \& Gonçalves, L. H. T. (2020). Vivência de sexualidade e HIV/AIDS na terceira idade. Research, Society and Development, 9(7), e483974256-e483974256.

Nardelli, G. G., Malaquias, B. S. S., Gaudenci, E. M., Ledic, C. S., Azevedo, N. F., Martins, V. E., \& Santos, Á. D. S. (2017). Conhecimento sobre síndrome da imunodeficiência humana de idosos de uma unidade de atenção ao idoso. Revista Gaúcha de Enfermagem, 37.

Nascimento, A. do., \& Cunha, D. (2020). Atividade física e espaço urbano: proposta de um centro de saúde para o idoso na cidade de Guarapuava-PR. Revista Journal of Health, 1, 2178-3594.

Oliveira, E. D. L., Neves, A. L. M. D., \& Silva, I. R. D. (2018). Sentidos de sexualidade entre mulheres idosas: relações de gênero, ideologias mecanicistas e subversão. Psicologia \& Sociedade, 30 .

Oliveira, R. L. de., Menezes Pequeno, B. E. de., Maconato, A. M., Veiga, D. D. O. C. da., Almeida, S. K. R. de, Cavalcanti, T. V. C., ... \& Oliveira, M. C. de. (2021). Velhice e sexualidade na pós-modernidade: um estudo sobre o corpo e o prazer. Research, Society and Development, 10 (2), e28410212628e28410212628.

Paula Rocha, J. de., \& Bós, Â. J. G. (2021). Perfil dos idosos e longevos do Brasil: análise da pesquisa nacional de saúde-IBGE 2013. EDIPUCRS.

Queiroga, S., Magalhães, S. I., \& Nogueira, C. (2018). Vivências e perceções de sexualidade de portuguesas com mais de 65 anos. Revista Estudos Feministas, 26.

Scult, M., Haime, V., Jacquart, J., Takahashi, J., Moscowitz, B., Webster, A., ... \& Mehta, D. H. (2015). A healthy aging program for older adults: effects on self-efficacy and morale. Advances in mind-body medicine, 29 (1), 26.

Silva, C. B. R., Almeida, I. R., de Toledo Lourenço, M. H., \& da Silva, T. F. G. (2015). A socialização primária e sua importância na integração do indivíduo no meio em que vive. Jornal Eletrônico Faculdade Vianna Júnior, 7 (Especial), 13-13.

Soares, C. P. G., \& Viana, T. V. (2016). Jovita Alves Feitosa: memórias que contam a história da educação nas prisões cearenses. Educação \& Formação, 1 (1), 140-158.

Soares, K. G., \& Meneghel, S. N. (2021). O silêncio da sexualidade em idosos dependentes. Ciência \& Saúde Coletiva, 26, 129-136.

Sousa, M. O. de., \& Sirelli, P. M. (2018). Neither saint nor sinner: new outlooks, old dichotomies in the reification of women. Serv. Soc. Soc, 132, 326-345. 
Research, Society and Development, v. 11, n. 3, e35011326560, 2022

(CC BY 4.0) | ISSN 2525-3409 | DOI: http://dx.doi.org/10.33448/rsd-v11i3.26560

Souza, C. L. D., Gomes, V. S., Silva, R. L. D., Silva, E. S. D., Alves, J. P., Santos, N. R., ... \& Ferreira, S. A. (2019). Envelhecimento, sexualidade e cuidados de enfermagem: o olhar da mulher idosa. Revista Brasileira de Enfermagem, 72, 71-78.

Vieira, K. F. L., Coutinho, M. D. P. D. L., \& Saraiva, E. R. D. A. (2016). A sexualidade na velhice: representações sociais de idosos frequentadores de um grupo de convivência. Psicologia: ciência e profissão, 36, 196-209.

Zanello, V., Fiuza, G., \& Costa, H. S. (2015). Saúde mental e gênero: facetas gendradas do sofrimento psíquico. Fractal: Revista de Psicologia, $27,238-246$. 